\title{
The Importance of Outdoor Activity and Place Attachment to Adolescent Development in Coös County, New Hampshire
}

\author{
Jayson Seaman and Sean McLaughlin
}

$\mathrm{H}$ istorically, the outdoors has played a key role in the culture and identity of people living in rural Coös County, New Hampshire. From economic mainstays such as paper and wood products manufacturing, to outdoor recreation and tourism involving both motorized and non-motorized pursuits, Coös County residents have long benefited from the area's abundant natural surroundings. As industries dependent on natural resource extraction have declined, however, the regionlike other northern forest areas-has experienced an economic downturn and corresponding outmigration. These economic and social factors have led young people to seek educational and employment prospects elsewhere, even if many still value the sense of community and the lifestyle opportunities that the outdoors provides. ${ }^{1}$

Coös County is currently undergoing an effort at place rebranding, shifting from a historical emphasis on resource extraction and manufacturing to a possible future identity as a recreational destination where one can pursue "grand adventures." This growing initiative builds on a long history of outdoor activity participation among citizens and proximity to rich outdoor amenities. It also is likely to have implications for the area's youth, who already demonstrate considerable involvement in outdoor activities; in a recent survey of the Coös Youth Study, after "hanging out," outdoor activities were ranked as the most common non-school-based activity by a margin of 21 percent, with twelfth graders participating in outdoor activities at a rate 20 percent higher than the national average for youth their age. ${ }^{3}$ Such data point to the key role outdoor activities play in defining the way youth in Coös County already spend personal time, making $4 \mathrm{H}$ and Scout programs, hiking, fishing, skiing, and snowmobiling

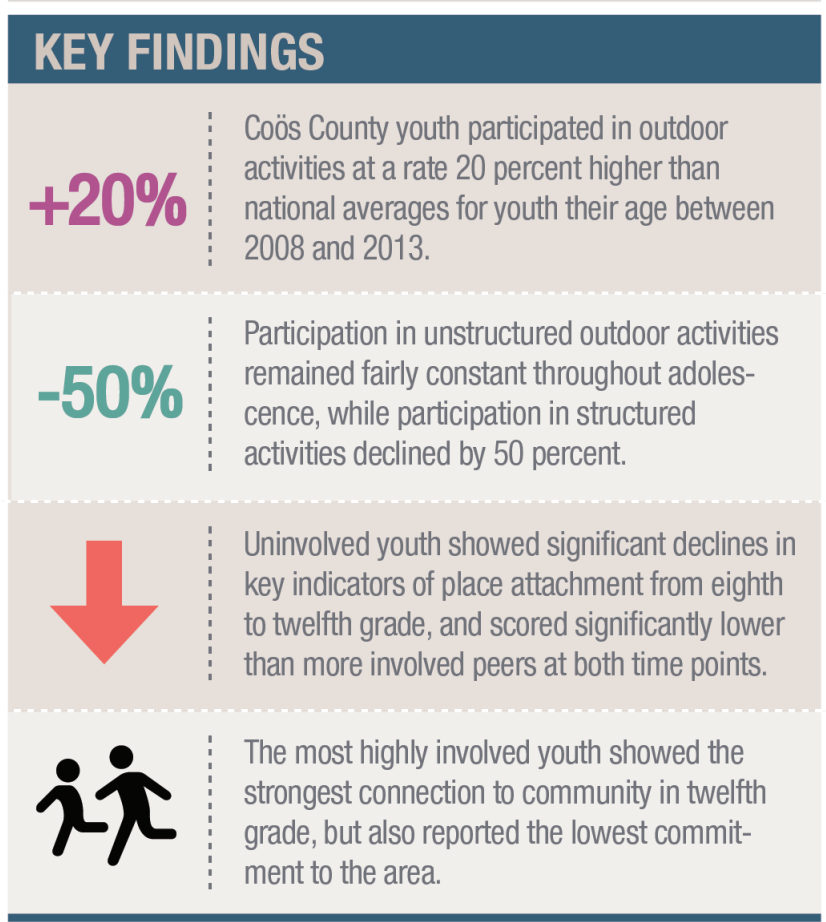

a notable context for understanding youth development, as well as a potential leverage point for enhancing positive development in evolving rural environments.

Generally speaking, activity involvement has been associated with positive development among youth. ${ }^{4}$ In Coös County, higher activity involvement among adolescents is positively related to educational attainment and future expectations, and negatively related to substance use. ${ }^{5}$ Research elsewhere suggests that outdoor-based activities in particular not only help youth form positive individual attributes, but also promote meaningful socialization into community traditions and values. ${ }^{6}$ 
A persistent issue facing adolescents in rural locations, though, is the conflict between life goals that might better be pursued elsewhere and an affinity for "place" that is fostered through involvement in meaningful activities and social networks. This aspect of development can be understood through the concept of place attachment, which represents a connection to one's community as well as its natural surroundings. Environmental and community psychologists have maintained that place attachment plays a role in overall well-being, yet in rural locations, it can also contribute to conflicting goals such as remaining in the local community versus pursuing more expansive educational or vocational opportunities elsewhere. ${ }^{7}$ Place attachment is particularly pertinent to youth development in Coös County, in which the outdoors has played such a central role in the region's identity and in children's upbringing, and where the maximization of meaningful outdoor activities could play a key role in helping youth imagine viable futures as the area's social and economic profile evolves. ${ }^{8}$

For this reason, the relationship between outdoor activity involvement, indicators of place attachment, and other outcomes in rural areas such as Coös County, New Hampshire, deserves consideration from a youth development standpoint. Studying this issue can help youth-focused organizations target specific sub-populations, tailor activities to suit changing preferences, and better coordinate services across age spans. To establish a baseline understanding of the way outdoor activities contribute to some of the key developmental tasks of adolescents in rural areas, this issue brief discusses the rates of participation in structured and unstructured outdoor activities as Coös County youth age, along with the relationship between outdoor activity involvement and indicators of place attachment throughout this period.

The analysis discussed in the brief is based on data collected between 2008 and 2013 as part of the Carsey Institute's Panel Study of Coös County youth. We concentrate on a subsample of 222 youth who completed surveys in both eighth and twelfth grade. Focusing on this cohort longitudinally offers a unique opportunity to examine how patterns differ among the same population of youth after the critical transition from middle to high school, when activity preferences and feelings of attachment to the community are most likely to fluctuate. ${ }^{9}$

\section{Declining Outdoor Activity Involvement}

The survey asked youth about their involvement during the preceding twelve months in $4 \mathrm{H}$ and Scouts (what we are calling structured activities in this brief) and other outdoor activities such as hiking, fishing, snowmobiling, and skiing (what we are calling unstructured activities). A minority of youth reported participating in structured outdoor activities in both eighth and twelfth grade, with a decline of 50 percent over that period. Conversely, a majority of participants reported involvement in unstructured outdoor activities, but this involvement also declines, albeit slightly, from eighth to twelfth grade. Figure 1 illustrates rates of participation in each activity type. These trends suggest that, while a large majority ( 80 percent) of youth continued to access outdoor activities throughout adolescence, only a small minority (9 percent) continued to pursue outdoor activities in structured settings as they aged.

FIGURE 1: RATES OF PARTICIPATION IN EACH OUTDOOR ACTIVITY TYPE OVER TIME

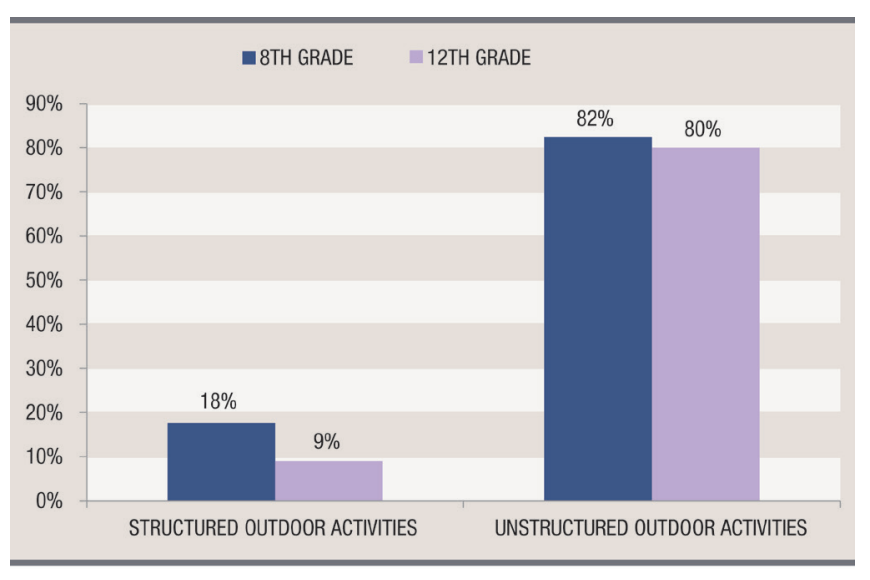

\section{Mixed Indicators of Place Attachment}

The survey also contained three question categories relevant to the notion of place attachment: (a) community connection, (b) commitment to the area, and (c) appreciation for the outdoors. "Community connection" represents a general feeling of engagement and belongingness in the community. "Commitment to the area" represents the importance to individuals of staying in the area in the future. "Appreciation for the outdoors" includes valuing access to outdoor amenities, as well as the area's natural beauty. ${ }^{10}$ Figure 2 presents percentages 
of youth who agree or strongly agree that they are committed to the area, connected to the community, and appreciate the outdoors at eighth and twelfth grade. Data show significant decline from eighth to twelfth grade in commitment to the area (59 percent to 41 percent) and connection to the community ( 79 percent to 70 percent), but a significant increase in appreciation for the outdoors (59 percent to 67 percent). These findings echo previous reports on this dataset (cited in the endnotes) but also suggest that youth participation in different types of outdoor activities plays an important part in shaping their attitudes toward the area.

\section{FIGURE 2: PERCENTAGE OF YOUTH IN THE OVERALL SAMPLE SAYING THEY AGREE OR STRONGLY AGREE WITH INDICATORS ABOUT PLACE ATTACHMENT*}

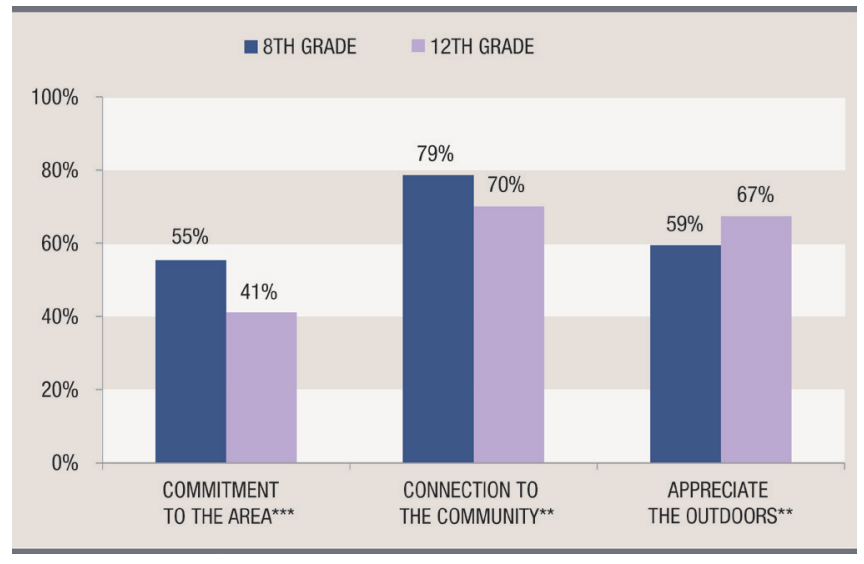

Note: Asterisks $\left(^{*}\right)$ indicate differences between groups significant at ${ }^{* *} \mathrm{p}<.01 ;{ }^{* * *} \mathrm{p}<.001$

\section{Differences Between Groups at Eighth and Twelfth Grade}

A close look at the data reveals significant variation in place attachment between youth involved to different extents in outdoor activities at eighth and twelfth grades. In Figures 3 and 4, overall scores in each category are broken into three levels of involvement: youth involved in both structured and unstructured outdoor activity, youth involved in either structured or unstructured outdoor activity, and youth involved in neither. The percentages of youth in each group agreeing and strongly agreeing with the indicators are represented on the graph. Differences between groups at each grade level were also examined by using a statistical test that helped reveal the extent to which varying levels of involvement in outdoor activity related to different aspects of place attachment in eighth and twelfth grades. ${ }^{11}$
FIGURE 3: PERCENTAGES OF YOUTH SAMPLE AGREEING OR STRONGLY AGREEING WITH PLACE ATTACHMENT INDICATORS BY LEVELS OF INVOLVEMENT IN OUTDOOR ACTIVITY AT 8TH GRADE (SHOWING DIFFERENCES BETWEEN GROUPS) $)^{12}$

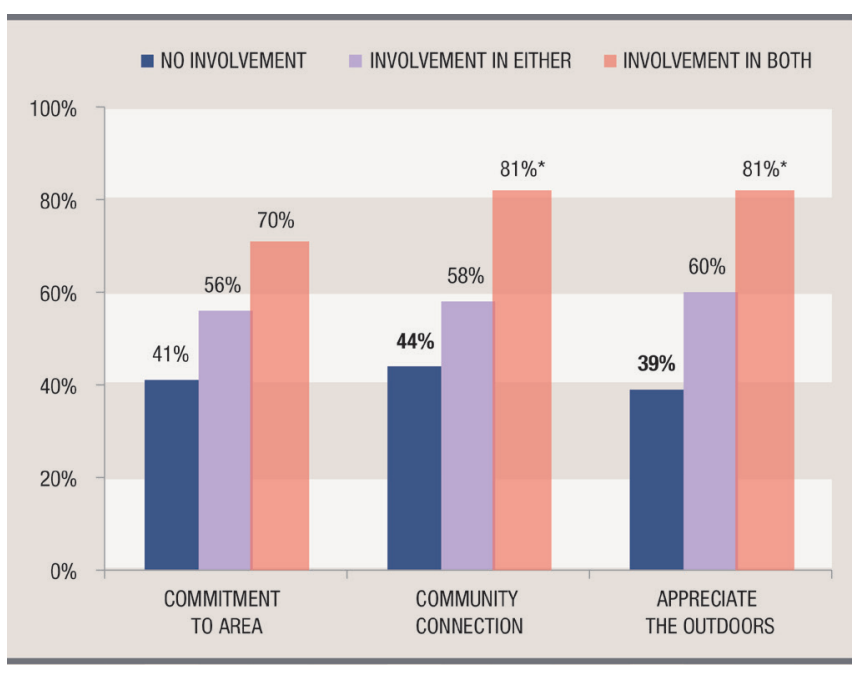

Notes: 1. An asterisk (*) indicates a significant difference in mean scores as compared to the next-lowest scoring group, at the $p<.05$ level or lower. Bold text indicates a difference that is significant from both other groups. 2. Sample size consists of 222 respondants.

FIGURE 4: PERCENTAGES OF YOUTH AGREEING OR STRONGLY AGREEING WITH PLACE ATTACHMENT INDICATORS BY LEVELS OF INVOLVEMENT IN OUTDOOR ACTIVITY AT 12TH GRADE (SHOWING DIFFERENCES BETWEEN GROUPS) ${ }^{13}$

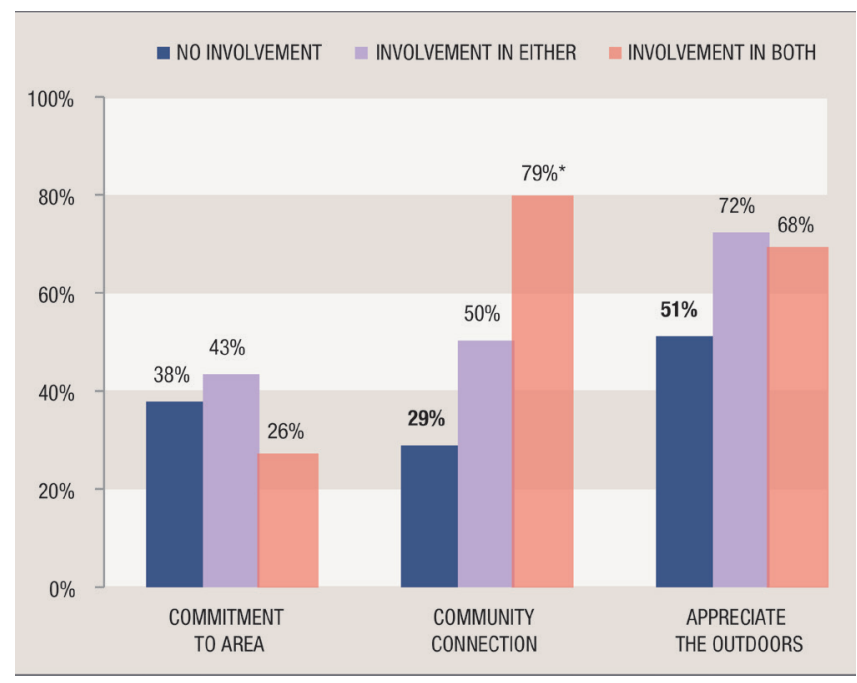

Notes: 1. An asterisk (*) indicates a significant difference in mean scores as compared to the next-lowest scoring group, at the $p<.05$ level or lower. Bold text indicates a difference that is signficant from both other groups. 2. Sample size consists of 222 respondants. 
Results from the analysis suggest strong connections between place attachment and outdoor activity involvement among Coös County youth at eighth and twelfth grade. Patterns imply that youth who were extensively involved in outdoor activities in early and late adolescence developed stronger connections to the community and affinity for its natural amenities, as uninvolved youth scored significantly lower than both groups of involved youth and decreased significantly in these areas over time. Between-group differences were most pronounced for youth involved in structured activities in eighth grade, but by twelfth grade, as interest in these activities declines or opportunities for meaningful involvement diminish, highly involved youth not only show a decline in appreciation for the outdoors, they report weaker commitments to the area than uninvolved youth. This suggests that structured activities foster especially strong feelings of place attachment in early adolescence, but ironically, this very quality might also contribute to the formation of life goals—such as educational attainment-that are better pursued elsewhere. Unstructured outdoor activities, which tend to be pursued more autonomously, seem to provide a meaningful and somewhat more stable link to the community for those who choose to pursue them, especially as youth progress through high school.

\section{The Role of Structured and Unstruc- tured Activities}

As the youth in the study aged, involvement declined and outdoor activity participation seemed to affect youth differently. Structured outdoor activities, which evidently fostered strong community connections at the middle school age, appear to have had the paradoxical effect of weakening commitments to the area as youth advance through adolescence, even as feelings of community connection remain comparatively high.

This finding might be attributable to the nature of structured activities such as Scouting and $4 \mathrm{H}$; youth who stay involved or become involved later tend to take on roles that require more ambitious leadership challenges and additional responsibility. In addition, youth motivations might change from having fun with friends in the outdoors in eighth grade, to building leadership or vocational skills by twelfth grade. Facing a realistic appraisal of the educational and employment opportunities in the area, youth could still value a connection to their community in an abstract sense but come to realize the limitations of staying in their home community past high school. On the other hand, youth who have independently come to enjoy recreational outdoor activities, perhaps through early experiences with family, ${ }^{14}$ might feel less centrally involved in community affairs, but be more open to staying close to the area because of the recreational opportunities it provides. Therefore, on the one hand, outdoor activities should be seen as a particularly important means of promoting positive development especially in the middle-school years, but some of the qualities that make them particularly influential-such as the promotion of feeling connected to one's communitymight also contribute to the tensions youth face as they mature and establish life goals in rural contexts. Helping youth navigate this tension as they age will be an important role for youth-serving organizations to play into the future.

\section{Conclusion}

The place rebranding of Coös County seeks to capitalize on its outdoor amenities by replacing traditional industries with recreation and tourism as potential growth sectors. ${ }^{15}$ While outdoor activities have always played a part in people's recreational lives, the importance to youth development of both structured and unstructured outdoor activities is likely to become even more pronounced as the region evolves economically and demographically. Strong positive relationships between outdoor activities and indicators of place attachment in the current analysis suggest that outdoor activities provide opportunities for youth to identify with community values and traditions as they age, creating a foundation from which they can establish meaningful life goals.

There are two main implications from this research. First, finding ways to generate interest among youth in outdoor activities as they transition through adolescence, and/or increasing the provision of other activities that link them in meaningful ways to the community, will extend developmental benefits to a wider range of youth. Youth program providers should consider expanding access to, and providing more opportunities for, structured and unstructured outdoor activities throughout Coös County. 
Second, pathways for development do not exist in a vacuum, but they are shaped by real educational and vocational opportunities that appear on the horizon as youth mature. It is likely that "place attachment" as an abstract sentiment has some beneficial qualities. Our analysis of data from the Coös Youth Study, however, suggests it might also contribute to the persistent tension between staying or leaving a local area to pursue opportunities elsewhere. One suggestion is to start seeing youth development and activity involvement as an issue that should be linked to wide-scale initiatives, such as the region's place rebranding, Stay-Work-Play NH, and other economic development programs. This requires communication and coordination among state and private agencies, youth-serving organizations such as $4 \mathrm{H}$ and the Appalachian Mountain Club, and institutions such as schools and community colleges. Policy makers and municipal leaders could help support the development and expansion of outdoor sectors that provide viable career futures for adolescents who acquire important skills and interests through their involvement in outdoor activities during their school years.

The research described in this brief supports the idea of cultivating youth interest in the outdoors and should be framed as not only a possible source of personal identity and place attachment, but also-insofar as activity involvement helps foster goal setting and affinity for the region's natural amenities-a potentially viable source of economic vitality for future generations of Coös residents.

\section{Endnotes}

1. Michele Dillon, "Stretching Ties: Social Capital in the Rebranding of Coös County, New Hampshire," Issue Brief No. 27 (Durham, NH: Carsey Institute, University of New Hampshire, 2011); Nena Stracuzzi, "Youth Aspirations and Sense of Place in a Changing Rural Economy: The Coös Youth Study," Issue Brief No. 11 (Durham, NH: Carsey Institute, University of New Hampshire, 2009).

2 Michele Dillon, "Stretching Ties."

3. Nena Stracuzzi, "Youth Aspirations"; Outdoor Foundation, "Outdoor Recreation Participation Report" (Boulder Colorado: Outdoor Foundation, 2013), available at: www. outdoorfoundation.org/pdf/ResearchParticipation2013.pdf.

4. Jacqueynne Eccles and Jennifer Appleton Gootman, "Community Programs to Promote Youth Development"
(Washington, DC: National Academies Press, 2002); Joseph L. Mahoney, Reed W. Larson, and Jaquelynne S. Eccles (Eds.), "Organized Activities as Contexts of Development: Extracurricular Activities, After School and Community Programs" (Mahwah, NJ: Lawrence Erlbaum Associates, 2005).

5. Erin Hiley Sharp, "Out of School Time Matters: Activity Involvement and Positive Development Among Coös County Youth," Issue Brief No. 17 (Durham, NH: Carsey Institute, University of New Hampshire, 2010); Erin Hiley Sharp, "Too Much Free Time: Coös County Youth Who Are Least Involved in Out-of-School Activities Are Most Likely to Use Drugs and Alcohol," Issue Brief No. 18 (Durham, NH: Carsey Institute, University of New Hampshire, 2010).

6. Matt D. Duerden and Peter A. Witt, "An Ecological Systems Theory Perspective on Youth Programming," Journal of Park \& Recreation Administration, 2 (2010), 108-120; Fran P. Mainella, Joel R. Agate, and Brianna S. Clark, "OutdoorBased Play and Reconnection to Nature: A Neglected Pathway to Positive Youth Development," New Directions for Youth Development, 130, (2011), 89-104.

7. Lynne C. Manzo and Douglas D. Perkins, "Finding Common Ground: The Importance of Place Attachment to Community Participation and Planning," Journal of Planning Literature, 4 (2006): 335-350; Lisa J. Crockett, Michael J. Shanahan, and Julia Jackson-Newsom, "Rural Youth: Ecological and Life Course Perspectives," Adolescent Diversity in Ethnic, Economic, and Cultural Contexts (Thousand Oaks, CA: Sage Publications, 2000), 43-74.

8. Cesar J. Rebellion, Nena F. Stracuzzi, and Melissa Burbank, "Youth Opinions Matter: Retaining Human Capital in Coös County," Issue Brief No. 19 (Durham, NH: Carsey Institute, University of New Hampshire, 2010); Nena F. Stracuzzi and Meghan L. Mills, "Teachers Matter: Feelings of School Connectedness and Positive Youth Development among Coös County Youth," Issue Brief No. 23 (Durham, NH: Carsey Institute, University of New Hampshire, 2010).

9. Monica K. Johnson, Robert Crosnoe, and Glen H. Elder, "Insights on Adolescence from a Life Course Perspective," Journal of Research on Adolescence, 21 (2011), 273-280.

10. Specific survey items in each category are as follows:

Commitment to the area (three items)_-"How important is it to YOU to: - live in the town where you grew up; - leave this area (negatively scored); - live close to your family."

Community connection (four items) - "I feel like part of my community." "I am happy to participate in community events." "I care about my community." "People in this community care about what kids think."

Appreciation for the outdoors (two items) _ “This community has so much to offer in terms of outdoor activities you could never get bored." "I love the natural beauty of my community." 
11. One-way analysis of variance (ANOVA) with Bonferroni post-hoc correction.

12. For No Involvement, $\mathrm{N}=39$; Involvement in Either, $\mathrm{N}=146$, and Involvement In Both, $\mathrm{N}=37$.

13. For No Involvement, $\mathrm{N}=45$; Involvement in Either, $\mathrm{N}=158$, and Involvement In Both, $\mathrm{N}=19$.

14. The 2013 Outdoor Foundation reports family as the strongest source of influence on youths' interest in outdoor activities, through age 17. Outdoor Foundation, "Special Report on Youth: The Next Generation of Outdoor Champions" (Boulder Colorado: Outdoor Foundation, 2013), available at: www.outdoorfoundation.org/pdf/ResearchYouth.pdf.

15. Michele Dillon, "Stretching Ties."

\section{About the Authors}

Jayson Seaman teaches in the Outdoor Education program at the University of New Hampshire and conducts research on the developmental impacts of outdoor activity participation (jayson.seaman@unh.edu).

Sean McLaughlin is a lecturer in recreation management at the University of New Hampshire, and a doctoral student in the Outdoor Education strand of the UNH's Education PhD Program.

\section{A cknowledgments}

The Coös Youth Study is supported by the National Science Foundation (Grant No. 1155797) and the Neil and Louise Tillotson Fund of the New Hampshire Charitable Foundation (Grant No. 79127). Any opinions, findings, conclusions, or recommendations expressed in this brief are those of the authors and do not necessarily reflect the views of the funders. This work relies also on the generous participation of the respondents, their families, teachers, school officials, and the communities involved in the Coös Youth Study. Special thanks to members of the Coös Youth Study research team for supporting this analysis, to Erin Hiley Sharp and Michele Dillon at UNH for helpful comments and suggestions on earlier drafts of this brief, and to Curt Grimm, Laurel Lloyd, Bruce Mallory, and Amy Sterndale at the Carsey Institute for their assistance and suggestions.

\section{$\triangle$ UNIVERSITY Ai of NEW HAMPSHIRE}

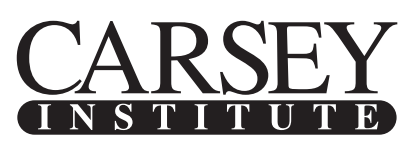

Building knowledge for families and communities

The Carsey Institute conducts policy research on vulnerable children, youth, and families and on sustainable community development. We give policy makers and practitioners timely, independent resources to effect change in their communities.

This work was supported by the The Neil and Louise Tillotson Fund of the New Hampshire Charitable Foundation.

Huddleston Hall

73 Main Street

Durham, NH 03824

(603) 862-2821

TTY Users: DIAL 7-1-1 OR 1-800-735-2964 (RELAY N.H.)

www.carseyinstitute.unh.edu 